\title{
RISK FACTORS AND PROTECTION IN TEACHERS
}

\author{
lacolino Calogero \\ Università degli Studi di Enna "Kore" \\ Faculty of Human and Society Sciences \\ calogero.iacolino@unikore.it \\ Giuseppina Ferracane \\ Università degli Studi di Enna "Kore" \\ Faculty of Human and Society Sciences \\ Ester Maria Concetta Lombardo \\ Università degli Studi di Enna "Kore" \\ Faculty of Human and Society Sciences \\ Rachele Isgrò \\ Università degli Studi di Enna "Kore" \\ Faculty of Human and Society Sciences \\ Salvatore Micieli \\ Università degli Studi di Enna "Kore" \\ Faculty of Human and Society Sciences \\ Brenda Cervellione \\ Università degli Studi di Enna "Kore" \\ Faculty of Human and Society Sciences
}

Fecha de Recepción: 24 Julio 2019 Fecha de Admisión: 25 Septiembre 2019

\section{ABSTRACT}

Background: The teaching profession is considered as a high-risk profession for the development of clinical outbreaks resulting from excessive workload, low self-satisfaction, students or a mediocre salary. Several studies have demonstrated that a high metacognitive capacity and an emotional recognition can positively influence the quality of life (Amirian \& Behshad, 2016; Iacolino et al., 2018; lacolino et al., 2019).

For this reason the emotional intelligence and the metacognition constructs have become very important in the last few years. Indeed, to know them can help to better understand the dysfunctional effects risk such as the "Burnout" and/or the secondary traumatic stress in this category (Kamenetz, 2015; Hydon et al., 2015). Method: The sample consists of 338 teachers with an average age of 50,19 (SD =7.91), to whom a self-report battery test was administered such as: Ad-hoc Socio-Registry Card; Link Burnout Questionnaire (LBQ; Santinello, Verzelletti \& Altoè, 2006); SelfReport Emotional Intelligence Test (SREIT; Craparo, Magnano \& Faraci, 2014); Secondary Traumatic 


\section{RISK FACTORS AND PROTECTION IN TEACHERS}

Stress (STSS-I; Setti \& Argentero, 2012); Metacognitive functions screening scale-30 (MFSS; Alaimo \& Schimmenti, 2013). Results: The results showed that there is not only a statistically significant positive correlation between the two metacognition scales (CDD and CDP) and emotional intelligence $(p<0.01)$, but there is also a statistically significant negative correlation between emotional intelligence and all scales of LBQ $(p<0.01)$. For this reason the literature data is certain. (Sprang, Craig \& Clark, 2011; Finkelhor et al., 2013). Conclusion: In conclusion, the aim of this work, which is to verify if the El and good metacognitive capacities could be considered as a protection factor, in order to mitigate possible disfunctional effects like the Burnout syndrom or the secondary traumatic stress, has been confirmed.

Keywords: teachers; El; metacognition; trauma; burnout

\section{INTRODUCTION}

The transmission of one's knowledge and the development of the appropriate skills, with the aim of putting young people in a position to know how to face the complexities of their present, has always been a burden of the teaching profession. Specially trained teachers are those who have the greatest influence in the field of civilization and play an important role in educating the community (Kayaalp, 2002), working hard to reach the end of a prosperous society (Celikten, Sanal \& Yeliz, 2005). It is clear, therefore, how this profession is important to change and develope the society (Ozpolat, 2005).

This profession has become at high risk of symptoms development over the years, as long as the category of nurses, doctors, psychologists, psychotherapists, social assistants, volunteer and professional emergency workers (Albanese et al., 2007a; Drago, 2006; lacolino \& Cervellione, 2019; lacolino et al., 2018). For this reason, clarifying and investigating on constructs, such as emotional intelligence and metacognition, can certainly help to understand the risk of burnout or secondary traumatic stress.

It is possible to distinguish two different interpretations of El. This happens because some authors classify it in terms of ability, while others understand it as a trait (Mayer, Salovey, \& Caruso, 2000; Warwick \& Nettelbeck, 2004). According to the "skill model", emotional intelligence is considered as an "ability to perceive, express, assimilate emotions, to understand and reason emotionally, and to regulate emotions in self and others" (Mayer \& Salovey , 1997, p.5), while supporters of the "trait model" define it as "a constellation of behavioural dispositions and self-perceptions concerning the ability to recognize, process and use emotionally charged information" (Petrides \& Furnham, 2003 , p. 40). They consider the El trait more as a characteristic of the personality than as a cognitive skill.

Teaching as well as being a rewarding career is also a very challenging profession; however, due to the management of legislative mandates and class management, individual psychophysical balances from time to time can jeopardize teacher's well-being and quality of life (Kamenetz, 2015; Martinetz, 2012). At a more specific level there is the student's incorrect behaviour, lack of autonomy, a feeling of isolation and other situations that can cause stress and create a very heavy burden that inevitably leads teacher to the onset of symptoms (Ávalos, 2011; Fernet, Guay, Senécal \& Austin, 2012; Skaalvik \& Skaalvik, 2011). This way, an emotional impoverishment and its subsequent dysregulation are evident (lacolino, Cervellione et al., 2018), involving different work figures that oscillate from generic operators to teachers in which, during the work, all the psychophysiological reactions caused by everyday fatigue compassion are connected (Hooper, Craig, Janvrin, Wetsel, \& Reimels, 2010).

In the field of educational institutions, teachers and school staff may be at risk of burnout developing and secondary traumatic stress, because they could respond to a school crisis or a commu- 
nity disaster or by teaching students, who bring their trauma experiences or stress to school, they can indirectly live experiences that upset them not only emotionally but also by changing behavioural patterns (Hydon et al., 2015).

\section{METHODOLOGY}

The objective of this article is to investigate risks and protection factors in the teacher, confirming and expanding the pre-existing literature (Amirian \& Behshad, 2016; Sharma \& Bedi, 2017). Emotions, both positive and negative, occur more frequently and with greater intensity in teachers (Back, 2008). These emotions affect their mental health, job satisfaction and their sense of self-efficacy (Pianta, 2006), falling into their attitudes and behaviour towards students (Ogernir, 2008). Perry and Ball (2007) revealed that teachers' reactions to positive and negative situations were moderated by their emotional intelligence. Therefore, emotionally intelligent teachers were more likely to identify personal emotional defects and to use a reflexive approach in situations of negative charge. Finally, they concluded that teachers with higher El were more likely to be effective teachers than their colleagues with low El indexes (Perry \& Ball 2007; Dolev \& Leshem, 2017).

Metacognitive strategies, on the other hand, are cognitions used to plan, monitor and evaluate the learning process (Veenman, Hout-Wolters \& Afflerbach, 2006; Zimmerman, 2011), coordinating and regulating cognitive and motivational processes, playing an essential role in the efficient and successful learning. The use of these strategies is supposed to be related to personal conditions and to the characteristics of the learning environment (Winne, 2001), therefore the role of the teachers will be to create a learning environment able to support the use metacognitive (Rieser, et al., 2016).

The aim is to verify if high levels of emotional intelligence and optimal metacognitive abilities are classified as a protection factor in order to mitigate the possible clinical onset that can oscillate from Burnout Syndrome to Secondary Traumatic Stress.

Therefore, according to the literature, it is hypothesized that:

$\mathrm{H} 1$ : there is a statistically significant positive correlation between metacognition (MFSS-30) and emotional intelligence (SREIT) (Alaimo \& Schimmenti, 2013; Craparo, Magnano, \& Faraci, 2014);

$\mathrm{H} 2$ : there is a statistically significant negative correlation between emotional intelligence (SREIT) and the psychophysical exhaustion subscales and professional ineffectiveness of the LBQ (Craparo, Magnano, \& Faraci, 2014; Santinello, 2010);

H3: there is a statistically significant negative correlation between the subscale ability to capture random relationships (CRC; MFSS) and the scale of activation of secondary traumatic stress (AR) (Argentero \& Setti, 2012; Alaimo \& Schimmenti, 2013).

\section{SAMPLE AND INSTRUMENT}

A battery of tests was administered, with the consent of the school administrators, to 338 preschool and primary school teachers in Sicily (Italy).

Each participant was informed about data collection according to the regulations in Italy (Legislative Decree 196/2003) and EU Regulation no. 679/2016 (“GDPR"). The research project was authorized by the Internal Review Board of the University of Enna "Kore" and complies with the Code of Ethics for psychology research.

The analyzed sample is composed of 338 teachers of which $91.7 \%$ are female and $8.3 \%$ are male with an average overall age of $50.19(\mathrm{SD}=7.91)$.

Most of the sample is conjugated $(77.5 \%)$ with a service years of about 20.90 years (SD $=8.85)$. The sample was then divided between primary school (67\%) and kindergarten (33\%) and the subjects mainly taught were for $26.3 \%$ childhood, $19.2 \%$ humanities, $16.6 \%$ prevalent teacher, $13.9 \%$ scientific subjects, $20.7 \%$ support teacher and 3.3\% English (see tab.01). 
Tab. 01 Demographics variables of the sample

\begin{tabular}{|c|c|c|}
\hline \multicolumn{3}{|c|}{$\begin{array}{c}\text { Total Sample } \\
(\mathrm{N}=338)\end{array}$} \\
\hline \multicolumn{3}{|c|}{ Age } \\
\hline \multicolumn{3}{|c|}{$\mathrm{M}=50,19, \mathrm{SD}=7,91$} \\
\hline \multicolumn{3}{|c|}{ Sex } \\
\hline & & $\%$ \\
\hline Male & 310 & 91,71 \\
\hline Female & 28 & 8,28 \\
\hline \multicolumn{3}{|c|}{ Nationality } \\
\hline Italian & 338 & 100 \\
\hline \multicolumn{3}{|c|}{ School } \\
\hline Kindergarten & 112 & 33,14 \\
\hline Primary & 226 & 66,86 \\
\hline \multicolumn{3}{|c|}{ Teaching subject } \\
\hline Infancy & 89 & 26,33 \\
\hline Humanistic disciplines & 65 & 19,23 \\
\hline Scientific disciplines & 47 & 13,91 \\
\hline English & 11 & 3,25 \\
\hline Prevailing teacher & 56 & 16,57 \\
\hline Support teacher & 70 & 20,71 \\
\hline \multicolumn{3}{|c|}{ Marital status } \\
\hline Single & 59 & 16,60 \\
\hline Married & 262 & 77,51 \\
\hline Separeted & 8 & 2,37 \\
\hline Divorced & 8 & 2,37 \\
\hline Widowed & 4 & 1,18 \\
\hline
\end{tabular}

The tools used for the research project were:

Ad hoc social partner questionnaire: including binary choice questions and open questions on the current age, sex, city of origin and teaching subject.

Emotional intelligence. Self-report emotional intelligence test (SREIT; Schutte et al., 1998; Italian Validation: Craparo, Magnano \& Faraci, 2014). The self-report Emotional Intelligence Test (SREIT, Schutte et al., 1998) is a self-report that measures the emotional capacities according to the El model of Salovey and Mayer (1990). SREIT has good internal consistency and test-retest reliability. The questionnaire consists of 33 items on a Likert scale with 5 points from 1 (completely disagree) to 5 (completely agreed). The sum of all the items constitutes the total score of the scale, which can vary from 33 to 165 (the highest scores indicate a greater emotional intelligence; the average scores for the female gender $M=121.86 S D=13.92$ and for the male gender $M=124.15 D S=12.30$ ). The internal coherence of the measure of emotional intelligence is between .87 and .90 .

Metacognition. Metacognitive Functions Screening Scale (MFSS-30; Alaimo \& Schimmenti, 2013). It is a self-report tool consisting of 30 likert-scale items from 0 to 3 from "absolutely false" to "absolutely true". The MFSS is useful for screening metacognitive functioning and investigates four abilities: Ability to recognize emotions (CRE), ability to capture random relationships (CRC), Decentralization Capacity (CDD) and weighting capacity (CDP). 
Secondary Traumatic Stress. Secondary Traumatic Stress (STSS-I; Italian Validation: Figley, 2002; Setti \& Argentero, 2012). It is a self-report tool consisting of 15 items that assesses Secondary Traumatic Stress in subjects exposed indirectly to traumatic events through a professional help relationship with a person who, on the other hand, has experienced it directly and is made up of two subscales (corresponding to the symptoms of PTDS): the intrusion scale (AI) and the Activation scale (AR). Each scale is evaluated based on the frequency reported by the subject in the last four weeks and each subject has the possibility to choose between five possible alternatives along a continuum on a 5-point Likert scale.

Burnout syndrome. Link Burnout Questionnaire (LBQ; Santinello, 2010). It is a self-report questionnaire that proposes new burnout indicators for those working in the helping professions. It is composed of 24 items and investigates four sub-dimensions and each of them has three items with positive polarity and three with negative polarity. The four dimensions are: Psychophysical exhaustion, relational deterioration, professional ineffectiveness and disillusionment. Through these four scales, thanks to the 6-point Likert scale response method, an individual profile of the state of malaise, which is able to guide resources and preventive and support interventions, is provided. Some items have an inverted score and the calculation procedure takes place through a first phase where the raw scores are calculated for each area by the sum, and at the low values will correspond the absence of the problem, while to the high ones the presence of it. Subsequently it is necessary to interpret the scores referring to the averages and the standard deviations of the distribution of the scores achieved by the sample to which the questionnaire was administered. Finally, to facilitate the interpretation of the score, the raw ones are converted to standardized standard points using stanine points ranging from 1 to 9 and with an average of 5 and a standard deviation of about 2 . The score ranging from 1 to 2 identified subjects with a positive work situation; score between 3 and 7 identifies subjects with a concern; score between 8 and 9 identifies subjects with high burnout compared to the regulatory group. For each profession there is a special table that allows the conversion of raw scores into stanine points.

\section{RESULTS}

From an initial analysis of the average scores of emotional intelligence (SREIT), of the subscales of the metacognition (MFSS-30) and of the burnout subscales (LBQ) it emerges that the sample has scores in emotional intelligence and in metacognition falling within the validation Italian test. However, the same cannot be said for the average subscale scores of burnout (LBQ) which are slightly lower than the Italian validation of the test (Tab. 02).

Therefore, it is possible to assert that, the sample taken in reference, feels motions that can be linked to a good emotional intelligence as well as good ability to recognize emotions, ability to grasp casual relationships, capacity for decentralization and capacity for weighting. These data indicate that the teachers are able to formulate appropriate inferences on the mental state of other people (lacolino, Ferracane, Cervellione \& Lombardo, 2019)

\begin{tabular}{lrr|rr} 
& \multicolumn{2}{c|}{$\begin{array}{c}\text { Italian validation } \\
\text { sample }\end{array}$} & \multicolumn{2}{c}{$\begin{array}{c}\text { Sample } \\
\text { N=338 }\end{array}$} \\
\cline { 2 - 5 } Tab.02 & \multicolumn{1}{c}{ M } & \multicolumn{1}{c}{ DS } & \multicolumn{1}{c}{ M } & \multicolumn{1}{c}{ DS } \\
\hline SREIT & 121,86 & 13,92 & 124,56 & 11,962 \\
MFSS - CRE & 9,77 & 3,69 & 10,70 & 4,175 \\
MFSS - CRC & 15,87 & 4,22 & 15,93 & 4,743 \\
MFSS - CDD & 24,28 & 5,33 & 27,27 & 4,529 \\
MFSS - CDP & 8,07 & 2,15 & 9,96 & 1,739 \\
Psycho-physical exhaustion & 17 & 5,4 & 14,45 & 5,272 \\
Relationship deterioration & 13,5 & 4,3 & 11,88 & 4,707 \\
Sense of professional failure & 15,7 & 5,5 & 10,84 & 3,826 \\
Disillusion & 15,2 & 6,2 & 10,83 & 5,279 \\
\hline
\end{tabular}




\section{RISK FACTORS AND PROTECTION IN TEACHERS}

The first hypothesis sets the objective of evaluating the existence of a statistically significant positive correlation between metacognition (MFSS-30) and emotional intelligence (SREIT). As can be seen from the table (Table 1), appears a statistically significant positive correlation with a Pearson $r p<0.01$ with all the subscales of the MFSS-30 except for the CRE subscales (ability to recognize emotions) and CRC (capacity of seize random relationships); this means that as the emotional intelligence increases, the ability of metacognition increases too. The second hypothesis set the objective of evaluating the existence of a statistically significant negative correlation between emotional intelligence (SREIT) and burnout subscriptions (LBQ). As can be seen from the table (Tab. 03) a statistically significant negative correlation is revealed with a Pearson r equal to $p<0.01$; it is understood that the increase of emotional intelligence lowers the psychophysical exhaustion, professional ineffectiveness, relational deterioration and disillusionment. Finally, the third hypothesis sets the existence of a statistically significant negative correlation between metacognition and secondary traumatic stress. The results show a statistically significant correlation between the CRC, CRE, CDD subscales (ability to understand random relationships, ability to recognize emotions and decentralization) and the activation subscale of secondary traumatic stress (AR). Furthermore, another statistically significant negative correlation emerges between the subset of the secondary traumatic stress intrusion (IN) and the subscales of the metacognition such as CRE and CRC (ability to recognize emotions and the ability to capture random relationships) with Pearson's $p<0,01$. These data indicate that as the metacognitive abilities increase, the secondary traumatic stress decreases (see Tab 03).

Tab.03 Correlazione tra SREIT, MFSS, LBQ e STSS

\begin{tabular}{|c|c|c|c|c|c|c|c|c|c|c|c|c|}
\hline 2. MFSS TOT & - &, $815^{* *}$ &, $834^{* *}$ &, $807^{* *}$ &, $307^{* *}$ &,$- 337^{* *}$ &,$- 256^{* *}$ &,$- 264^{* *}$ &,$- 325^{* *}$ &,$- 266^{* *}$ &,$- 298^{* *}$ &,$- 165^{* *}$ \\
\hline 3. CRE & & - &, $630^{* *}$ &, $504^{* *}$ &,- 022 &,$- 227^{* *}$ &,$- 190^{* *}$ &,$- 171^{* *}$ &,$- 195^{* *}$ &,$- 181^{* *}$ &,$- 265^{* *}$ &,$- 200^{* *}$ \\
\hline 4. CRC & & & - &, $455^{* *}$ &, $110^{*}$ &,$- 232^{* *}$ &,$- 177^{* *}$ &,$- 184^{* *}$ &,$- 207^{* *}$ &,$- 185^{* *}$ &,$- 242^{* *}$ &,$- 193^{* *}$ \\
\hline 6. CDP & & & & & - &,$- 170^{* *}$ &,$- 111^{*}$ &,$- 191^{* *}$ &,$- 181^{* *}$ &,- 090 &,- 066 & ,070 \\
\hline 7. LBQ TOT & & & & & & - &, $849^{* *}$ &, $821^{* *}$ & $688^{* *}$ &, $868^{* *}$ &, $475^{* *}$ &, $217^{* *}$ \\
\hline $\begin{array}{l}\text { 8. LBQ - Psycho-physical } \\
\text { exhaustion }\end{array}$ & & & & & & & - &, $663^{* *}$ &, $414^{* *}$ &, $642^{* *}$ &, $499^{* *}$ &, $202^{* *}$ \\
\hline $\begin{array}{l}\text { 9. LBQ - Relationship } \\
\text { deterioration }\end{array}$ & & & & & & & & - &, $402^{* *}$ &, $600^{* *}$ &, $429^{* *}$ &, $196^{* *}$ \\
\hline 13. STSS - Intrusion & & & & & & & & & & & & - \\
\hline
\end{tabular}

SREIT Self report Emotional Intelligence, MFSS Metacognitive Functional Screening Scale, LBQ Link Burnout Questionnaire, STSS Stress Traumatic Secondary Scale; ${ }^{*} \mathrm{p}<.05 ; * * \mathrm{p}<.01$ (due code).

\section{DISCUSSION}

The first hypothesis investigates on the existence of a statistically significant positive correlation between metacognition and emotional intelligence. It is possible to state that a high capacity of metacognition and a high emotional intelligence are able to mitigate clinical outbreaks such as burnout and secondary traumatic stress. It's the same increasing the ability to relate to the others (Amirian \& Behshad, 2016; Naqvi, et al. 2016; Poulou, 2016; lacolino et al., 2019). 
The second hypothesis was to investigate the presence of a statistically significant negative correlation between emotional intelligence and the subscales of the Link Burnout Questionnaire. The results show that teachers with high emotional intelligence are less likely to develop symptoms related to burnout such as psychophysical exhaustion, professional ineffectiveness, relational deterioration and disillusionment (Veazi \& Fallah, 2011; Przybylska, 2016; Zysberg, et al., 2017). Therefore, correlation analyzes confirm our hypothesis.

Finally, the third hypothesis investigate on the existence of a statistically significant negative correlation between metacognition and secondary traumatic stress. It seems clear that teachers who present high levels of stress transformed into symptoms of anxiety, confusion, sadness, shame, horror and various physical disorders cannot distinguish between what is real and what is not, so it is difficult to build relationships between behaviour and goals that can achieve effective results for understanding and planning educational programs.

Therefore, from the results of the present study it emerges how important the metacognitive capacities and the emotional intelligence are from mitigating potential dysfunctional effects such as secondary traumatic stress and the symptoms of burnout, classifying the first as protective factors (lacolino, Ferracane, Cervellione \& Lombardo, 2019).

\section{Limitations of this study and future prospects}

This research, despite the significant results, has limits to be taken into consideration. Some of them are, for example, the small number of the sample and the high tax of women.

It would desirable for future studies:

- To expand the sample to better analyze the data;

- To try to make the sample as homogeneous as possible;

- To extend the study to secondary school teachers, to better examine the workload differences in the various school classifications.

\section{CONCLUSION}

From what is shown in this article, the objective was to evaluate emotional intelligence within the school context, focusing primarily on the teachers' group of kindergarten and primary schools.

Many have talked about Emotional Intelligence as a protective factor because it allows one to perceive and express emotions, but it is also the ability to be self-aware of them.

From a first research in the literature, it has been shown how a high emotional intelligence acts as a protective factor for possible dysfunctional effects such as burnout and / or secondary traumatic stress. Many studies have linked this construct, not only with burnout and secondary traumatic stress, but also in relation to other variables such as the years of teaching, the gender difference and the teaching class. From this first research, therefore, it was found that these factors negatively influence, leading to job dissatisfaction. Therefore, a resolution could be the implementation of SEL (programs to expand El) for the teaching profession.

The possession of individual functional factors, such as excellent adaptive coping strategies (lacolino \& Cervellione, 2019) and good metacognitive skills, positively influences El, lowering the risk of job dissatisfaction and professional ineffectiveness and the development of secondary traumatic stress symptoms.

The collected data allowed to take a first evaluation in order to establish what risk is and what protection in the category of teachers.

From the results of the research it is possible to observe how fundamental is to create intervention projects to support teachers in the development of emotional intelligence. 


\section{RISK FACTORS AND PROTECTION IN TEACHERS}

\section{BIBLIOGRAPHIC REFERENCES}

Alaimo, S. M., \& Schimmenti, A. (2013). Metacognitive functions screening scale-30 items (mfss30): un nuovo strumento per lo screening del funzionamento metacognitivo. Psichiatria $e$ Psicoterapia, 32(3).

Albanese, O., Doudin, P.A., Farina, E, Fiorilli, C. \& Strepparava, M.G. (2007), Rischi e risorse nella professione insegnante, in Delle Fave A. (a cura di), La condivisione del benessere. II contributo della psicologia positiva. Milano: Franco Angeli.

Amirian, S. M. R., \& Behshad, A. (2016). Emotional intelligence and self-efficacy of Iranian teachers: A research study on university degree and teaching experience. Journal of Language Teaching and research, 7(3), 548-558. Doi: http://dx.doi.org/10.17507/jltr.0703.16

Avalos, B. (2011). Teacher professional development in teaching and teacher education over ten years. Teaching and teacher education, 27(1), 10-20.

Back, S. 2008. "Is Training Un-necessary? The Uniqueness of Academic Teacher-training Programs." In Crisis in Teacher Education: Reasons, Problems and Possible Solutions [in Hebrew], edited by D. Kfir and T. Ariav, 251-301. Jerusalem: VanLeer Institute.

Çelikten, M., anal, M., \& Yeni, Y. (2005). Teaching profession and its characteristics. Erciyes University, Institute of Social Sciences Journal, 19(2), 207-237.

Craparo, G., Magnano, P., \& Faraci, P. (2014). Psychometric properties of the italian version of the self-report emotional intelligence test (SREIT). TPM: Testing, Psychometrics, Methodology in Applied Psychology, 21(2).

Dolev, N., \& Leshem, S. (2017). Developing emotional intelligence competence among teachers. Teacher Development, 21(1), 21-39. http://dx.doi.org/10.1080/13664530.2016.1207093

Drago, R. (2006), Presente e futuro degli insegnanti: Rassegna della ricerca internazionale, Psicologia dell'Educazione e della formazione, 8, 199-224.

Fernet, C., Guay, F., Senécal, C., \& Austin, S. (2012). Predicting intraindividual changes in teacher burnout: The role of perceived school environment and motivational factors. Teaching and teacher education, 28(4), 514-525.

Figley, C. R. (2002). Compassion fatigue: Psychotherapists' chronic lack of self care. Journal of clinical psychology, 58(11), 1433-1441.

Furnham, A., \& Petrides, K. V. (2003). Trait emotional intelligence and happiness. Social Behavior and Personality: an international journal, 31(8), 815-823.

Hooper, C., Craig, J., Janvrin, D. R., Wetsel, M. A., \& Reimels, E. (2010). Compassion satisfaction, burnout, and compassion fatigue among emergency nurses compared with nurses in other selected inpatient specialties. Journal of emergency nursing, 36(5), 420-427.

Hydon, S., Wong, M., Langley, A. K., Stein, B. D., \& Kataoka, S. H. (2015). Preventing secondary traumatic stress in educators. Child and Adolescent Psychiatric Clinics, 24(2), 319-333.

Iacolino C., Cervellione B., Pellerone M., Di Fresco C., \& Lombardo E.M.C.(2018a). The Tertiary victims: risk factors and protection. Mediterranean Journal of Clinical Psychology, 6(2).

Iacolino C., Lombardo E.M.C., Cervellione B., Mannino G., Micieli S. (2018b). La dipendenza da Internet: Il fenomeno dell'IGD in un campione non clinico di videogiocatori di MOBA e MMORPG. Narrare i Gruppi, 13(2), 225-260.

lacolino, C., \& Cervellione, B. (2019). Gli operatori dell'emergenza. Fattori di Rischio e di Protezione. Milano: Franco Angeli.

Iacolino, C., Ferracane, G., Cervellione, B., Lombardo, E.M.C. (2019). Emozione e cognizione: le competenze trasversali in un campione di insegnanti. XIX Congresso Nazionale SIO "Orientamento inclusivo e sostenibile: ricerche, strumenti, azioni". 17-19, Ottobre, Catania/Enna. 
Iacolino, C., Lombardo, E. M., Cervellione, B., Mannino, G., \& Micieli, S. (2019). Internet Addiction Disorder: Internet Gaming Disorder in a Nonclinical Sample Of Moba And Mmorpg Videoplayers. World Futures, 1-27.Doi: 10.1080/02604027.2019.1654775.

Kamenetz, A. (2015). Non academic skills are key to success. But what should we call them. National Public Radio.

Martinez, L. F. (2012). Presenteeism and burnout among teachers in public and private Portuguese elementary schools. The International Journal of Human Resource Management, 23(20), 43804390.

Mayer, J. D., Caruso, D. R., \& Salovey, P. (2000). Selecting a measure of emotional intelligence: The case for ability scales. In R. Bar-On \& J. D. A. Parker (Eds.), The handbook of emotional intelligence: Theory, development, assessment, and application at home, school, and in the workplace (pp. 320-342). San Francisco, CA, US: Jossey-Bass.

Mayer, J. D., Salovey, P., Salovey, P., \& Sluyter, D. (1997). Emotional development and emotional intelligence: Implications for educators. What is emotional intelligence, 3-31.

Naqvi, I. H., Iqbal, M.\&Akhtar, S. N. (2016). The Relationship between Emotional Intelligence and Performance of Secondary School Teachers. Bulletin of Education and Research, 38,209-224.

Ogernir, B. (2008). "Investigating the Relationships between Emotional Intelligence and Preservice Teachers' View of Effective Teaching." PhD diss., Pennsylvania State University.

Özpolat, A. (2005). Ö retmenlik mesle indeki de i melerin tarihsel ve toplumsal ba lamı. Milli E itim Dergisi, 166, 30-34.

Perry, C., \& Ball, I. (2007). Dealing constructively with negatively evaluated emotional situations: The key to understanding the different reactions of teachers with high and low levels of emotional intelligence. Social Psychology of Education, 10(4), 443-454.

Pianta, R. C. (2006). "Classroom Management and Relationships between Children and Teachers: Implications for Research and Practice." In Handbook of Classroom Management: Research, Practice and Contemporary Issues, edited by C. M. Everston and C. S. Weinstein, 685-710. Mahwah: Lawrence Erlbaum Associates.

Poulou, M. S. (2017). Social and emotional learning and teacher-student relationships: Preschool teachers' and students' perceptions. Early Childhood Education Journal, 45(3), 427-435.

Przybylska, I. (2016). Emotional Intelligence and Burnout in the Teaching Profession. New Educational Review. 43 (1), 41-52. Doi: 10.15804/tner.2016.43.1.03

Rieser, S., Naumann, A., Decristan, J., Fauth, B., Klieme, E., \& Büttner, G. (2016). The connection between teaching and learning: Linking teaching quality and metacognitive strategy use in primary school. British Journal of Educational Psychology, 86(4), 526-545.

Salovey, P., \& Mayer, J. D. (1990). Emotional intelligence. Imagination, cognition and personality, $9(3), 185-211$.

Santinello, M. (2010). LBQ: Link, burnout, questionnaire. Milano: Giunti, OS Organizzazioni Speciali.

Schutte, N. S., Malouff, J. M., Hall, L. E., Haggerty, D. J., Cooper, J. T., Golden, C. J., \& Dornheim, L. (1998). Development and validation of a measure of emotional intelligence. Personality and individual differences, 25(2), 167-177.

Setti, I., \& Argentero, P. (2012). Vicarious trauma: A contribution to the Italian adaptation of the Secondary Traumatic Stress Scale. Bollettino di Psicologia Applicata, 264, 58-64.

Sharma, V., \& Bedi, M. (2017). Emotional intelligence and occupational stress among teaching professionals in India. GYANODAYA: The Journal of Progressive Education, 10(1).

Skaalvik, E. M., \& Skaalvik, S. (2011). Teacher job satisfaction and motivation to leave the teaching profession: Relations with school context, feeling of belonging, and emotional exhaustion. 
Teaching and teacher education, 27(6), 1029-1038.

Veenman, M. V., Van Hout-Wolters, B. H., \& Afflerbach, P. (2006). Metacognition and learning: Conceptual and methodological considerations. Metacognition and learning, 1(1), 3-14.

Warwick, J., \& Nettelbeck, T. (2004). Emotional intelligence is...? Personality and Individual Differences, 37, 1091-1100. Doi:10.1016/j.paid.2003.12.003

Winne, P. H. (2001). Self-regulated learning viewed from models of information processing. Selfregulated learning and academic achievement: Theoretical perspectives, 2, 153-189.

Zimmerman, B. J. (2011). Motivational Sources and Outcomes of Self-Regulated Learning and Performance: Graduate Center of City University of New York. In Handbook of self-regulation of learning and performance (pp. 63-78). Routledge.

Zysberg, L., Orenshtein, C., Gimmon, E., \& Robinson, R. (2017). Emotional intelligence, personality, stress, and burnout among educators. International Journal of Stress Management, 24(S1), 122. 